\title{
Eight years of an outstanding experience as the Editor-in- Chief of the Journal of Applied Oral Science (JAOS)
}

Over the last eight years, I had the privilege of being the Editor-in-Chief of the Journal of Applied Oral Science (J AOS), one of the richest experiences in my scientific-administrative career. With an impact factor of 0.803 in the Journal Citation Reports (JCR), JAOS is currently ranked in the $66^{\text {th }}$ position among the 82 journals in the Dentistry, Oral Surgery $\&$ Medicine category. This is the $2^{\text {nd }}$ best performance of the journal since its inclusion in this prestigious international database, with a low level of self-citations and a small number of articles authored by the faculty, students and researchers of the Bauru School of Dentistry / University of São Paulo (FOB/USP), its official publisher. Another important fact is related to the ranking among the Brazilian journals indexed in JCR; out of 106 national journals that take part in this database JAOS occupies the $33^{\text {rd }}$ place. Also as far as the internationalization, it is worth mentioning the indexations in other respected databases such as SciELO, SCOPUS, MEDLI NE/ PubMed, Web of Science and PubMed Central. The publication of ahead of print articles and the adoption of ScholarOne as the online submission system as well as the Digital Object Identifier (DOI) are other great achievements of the JAOS.

It gives me joy and proud to look back and realize all this evolution of our journal, but at the same time I have the obligation to acknowledge all of those people who, in a great team work, contributed to this success. It would be impossible to make such achievements by myself.

I have to highlight the vision and confidence of the Deans of FOB, Professor Luiz Fernando Pegoraro, who appointed me for this position in 2006, Professor José Carlos Pereira and Professor Maria Aparecida de Andrade Moreira Machado. It is remarkable the enthusiasm, freedom and unconditional support that these Deans gave us to adopt editorial policies aiming at increasing the international visibility of the journal and the quality of the papers published. I also have to emphasize the financial support provided to the journal by FOB, Rectory of USP and public agencies such as CNPq, CAPES and FAPESP, which actually made the changes possible.

Also of great importance was the participation of authors, who chose the JAOS to publish their works, and the reviewers, who anonymously and diligently gave their opinions to improve the quality of the articles submitted to the journal.

The Associate Editors, appointed by our Deans due to the growing interest of the scientific community in the journal, played an important role in the management and review of the submissions. As respected authorities in their areas of expertise, they significantly contributed for a reduction in the response time to the authors and consequently in the waiting time for publication of the articles. I also highlight the importance and commitment of Dr. Gustavo Pompermaier Garlet, the CoEditor-in-Chief, a dedicated colleague who over the last two years worked tirelessly to help me manage all the submissions to the journal. During this period he was also able to get familiar with the administrative routine.

Another major reason for JAOS's success is the dedication and professionalism of our employees Valéria Cristina Trindade Ferraz, José Roberto Plácido Amadei, Deborah Schmidt Capella Junqueira, Sônia Cláudia Antonelli Pirola, Neimar Vitor Pavarini, Rubens Kazuo Kato and Allan Rodrigo Dias, brilliantly leaded by the first, who in fact were responsible for the execution of all the changes aforementioned. In this team I also include Zelma Batista Borges, Financial Technical Assistant, who perfectly observed the legal aspects for the good use of the public funding to the JAOS. I hope this admired and respected team accepts my deepest apologies for the requests I made more emphatically.

Finally, in this transition period, I want to send my best wishes to Dr. Gustavo Pompermaier Garlet, Editor-in-Chief, and Dr. Karin Hermana Neppelenbroek, Co-Editor-inChief, appointed by our Dean on November $11^{\text {th }}, 2014$. I predict great achievements from their leadership such as the adoption of a plagiarism detection software. I humbly offer them my help whether they find it convenient.

Now, I am ready for new challenges!

Thank you for your attention,

CARLOS F. SANTOS 